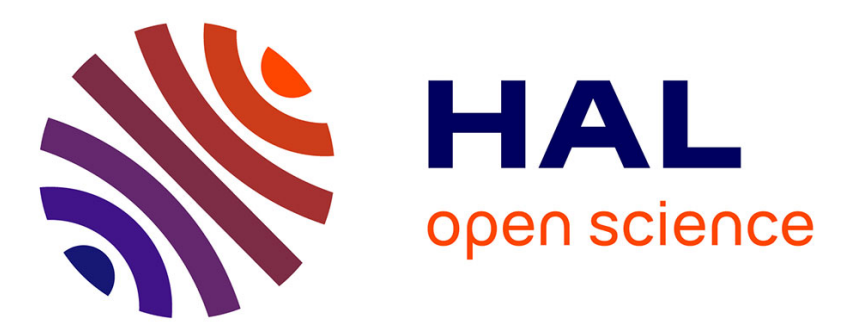

\title{
Does an additional load modify the Anticipatory Postural Adjustments in gait initiation?
}

Teddy Caderby, Georges Dalleau, Pierre Leroyer, Bruno Bonazzi, Daniel Chane-Teng, Manh-Cuong Do

\section{- To cite this version:}

Teddy Caderby, Georges Dalleau, Pierre Leroyer, Bruno Bonazzi, Daniel Chane-Teng, et al.. Does an additional load modify the Anticipatory Postural Adjustments in gait initiation?. Gait \& Posture, 2013, 37 (1), pp.144-146. 10.1016/j.gaitpost.2012.06.012 . hal-00811628v2

\section{HAL Id: hal-00811628 \\ https://hal.science/hal-00811628v2}

Submitted on 27 Oct 2016

HAL is a multi-disciplinary open access archive for the deposit and dissemination of scientific research documents, whether they are published or not. The documents may come from teaching and research institutions in France or abroad, or from public or private research centers.
L'archive ouverte pluridisciplinaire HAL, est destinée au dépôt et à la diffusion de documents scientifiques de niveau recherche, publiés ou non, émanant des établissements d'enseignement et de recherche français ou étrangers, des laboratoires publics ou privés. 


\title{
Does an additional load modify the Anticipatory Postural Adjustments in gait initiation?
}

\author{
Teddy Caderby a,*, Georges Dalleau ${ }^{\mathrm{a}}$, Pierre Leroyer ${ }^{\mathrm{a}}$, Bruno Bonazzi ${ }^{\mathrm{a}}$, Daniel Chane-Teng ${ }^{\mathrm{b}}$, \\ Manh-Cuong Do ${ }^{c}$ \\ ${ }^{a}$ CURAPS-DIMPS, UFR des Sciences de l'Homme et de l'Environnement, Université de la Réunion, 97430 Le Tampon, Ile de la Réunion, France \\ ${ }^{\mathrm{b}}$ Centre Ylang Ylang Réadaptation Fonctionnelle Jeanne d'Arc, 97420 le Port, Ile de La Réunion, France \\ ${ }^{\mathrm{c}}$ Laboratoire CIAMS, UR 4532, UFR STAPS, Bât 335, Université Paris-Sud, 91405 Orsay Cedex, France
}

\begin{abstract}
A B S T R A C T
The objective of the study was to examine whether and how an additional load affects the Anticipatory Postural Adjustments (APA) in gait initiation in able-bodied individuals. Nineteen healthy participants initiated gait at a self-selected speed in two conditions: unloaded and with an overload of $15 \%$ body weight. The APA duration, the forward impulse of the APA and the duration of gait initiation increased significantly with the overload, while the other variables did not change. These results indicate that during gait initiation with overload, able-bodied subjects modulate the APA duration to produce a higher forward impulse in order to achieve the steady-state gait at the end of the first step. These findings could have implications in clinical practice where overloading could be used to improve the gait initiation in pathologic patients. Further investigations are needed to confirm this suggestion.
\end{abstract}

\section{Introduction}

Gait initiation is the transition between the upright posture and the steady-state gait. This process consists of two phases, namely, a postural phase (called Anticipatory Postural Adjustments (APA)) followed by an execution phase [1]. The APA contribute to postural stability [2] and create the propulsive forces necessary to reach the steady-state gait at the end of the first step $[1,3]$.

It is known that load carriage alters the postural control mechanisms in quiet standing [4] and affects the balance during walking [5], but its effect on postural control in gait initiation is unclear. To the best of our knowledge, though a recent study has shown that body weight affects gait initiation [6], the effect of an external load on this process has not yet been investigated. Gait initiation with an additional mass should require higher propulsive forces that could affect the APA organization. A better understanding of the effect of load on APA in gait initiation could have

\footnotetext{
* Corresponding author at: CURAPS-DIMPS, UFR des Sciences de l'Homme et de l'Environnement, Université de la Réunion, 117 rue du Général Ailleret, 97430 Le Tampon, Ile de la Réunion, France. Tel.: +262 2625795 91; fax: +262 262579571. E-mail addresses: teddy.caderby@univ-reunion.fr, caderby.t@hotmail.fr (T. Caderby)
}

implications for the rehabilitation of gait initiation problems in patient populations (e.g., Parkinsonian patients [7,8]).

The objective of the study was to examine whether and how an additional load affects the APA in gait initiation in able-bodied adults.

\section{Methods}

Nineteen healthy subjects (mean age $20.3 \pm 1.1$ years, height $176 \pm 8 \mathrm{~cm}$, weight $70 \pm 10 \mathrm{~kg}$ ) participated in the experiment. All participants gave their consent after being fully informed of the test procedure approved by the Institutional Ethics Committee.

Two force-plates ( $400 \mathrm{~mm} \times 600 \mathrm{~mm}$, AMTI, USA) embedded in series in a fivemeter walkway recorded the ground reaction forces and moments at $1000 \mathrm{~Hz}$. An optoelectronic system (VICON 460, UK) collected the spatial data of two skin markers placed at the subject's heels $(200 \mathrm{~Hz})$. All signals were synchronized and transmitted to an acquisition system.

Subjects stood upright, barefoot and as still as possible on the first force-plate. The position of the feet was marked on this force-plate so that the subjects kept the same position for each trial. At the experimenter's signal, they walked at a selfselected speed to the end of the walkway. The swing leg was self-selected and remained the same during all the trials. Six trials were performed without overload (UC) and with an overload (OC). The order of the conditions was randomized across subjects. Familiarization trials were provided in each load condition. A threeminute rest was imposed between conditions. Fig. 1 represents the experimental setting.

The overload was placed at the height of the body center of mass and consisted of a diving belt to which weights were added symmetrically with respect to the frontal and sagittal planes to reach the desired loading. The chosen overload mass was 


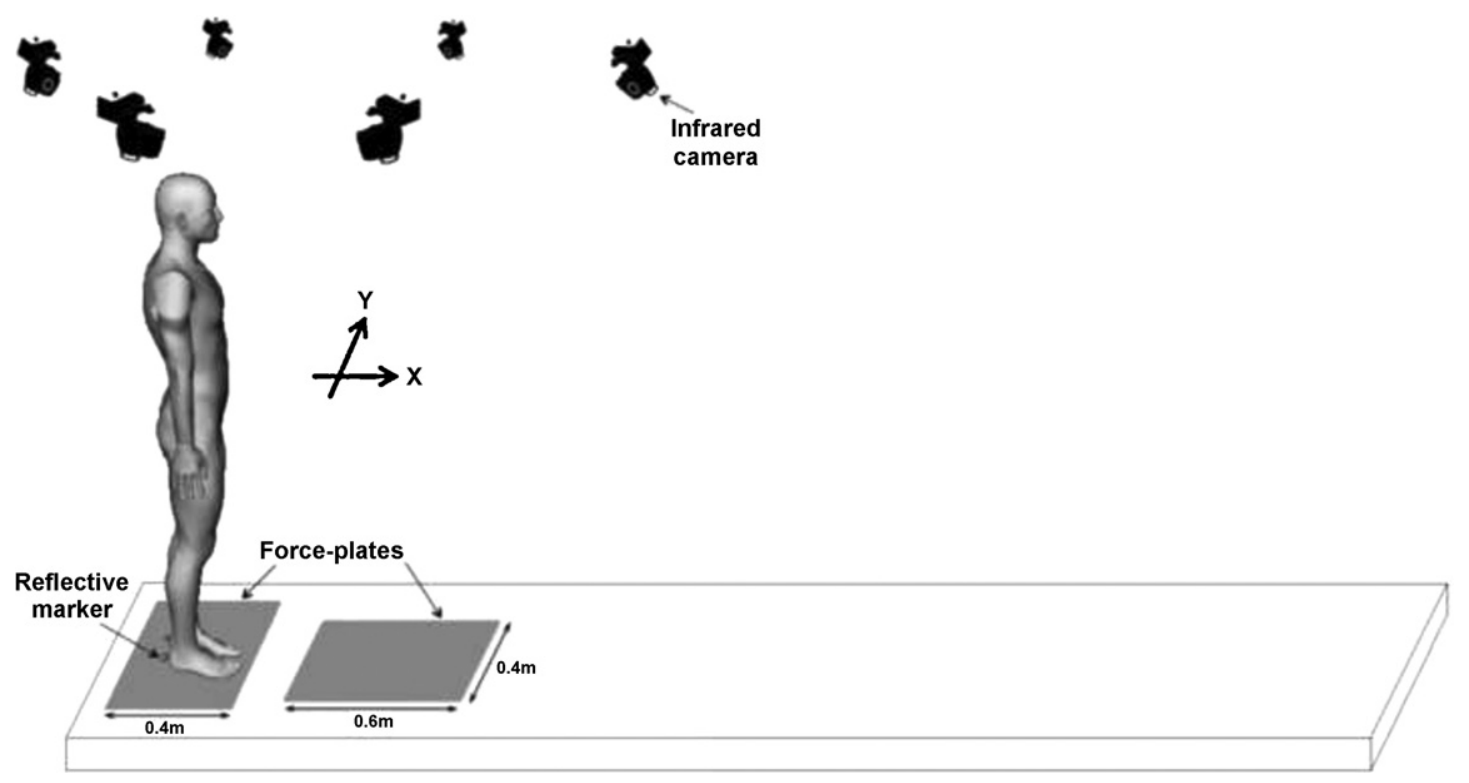

Fig. 1. Schematic illustration of the experimental set up.

fifteen percent of the subject's body mass as this magnitude has been shown to affect gait kinematics [9].

The anteroposterior Center of Gravity (CG) velocity and coordinates of Center of Pressure (CP) were calculated from the force-plate data [10]. The heel-off occurrence of the swing limb was determined from the kinematics of the heel marker [11]. Seven dependent variables were calculated (Fig. 2):

- APA duration $\left(D_{\mathrm{APA}}\right)$, i.e. time between the onset of the first dynamic phenomena $\left(t_{0}\right)[12]$ and the heel-off of the swing limb $\left(t_{\mathrm{HO}}\right)$.

- Anteroposterior CG velocity at $t_{\mathrm{HO}}\left(V_{\mathrm{HO}}\right)$.

- Maximal backward shift of CP during the APA ( $\left.x P_{\max }\right)$.

- Forward impulse of the APA (Imp $\left.p_{\mathrm{AP}}\right)$, calculated by integrating the anteroposterior ground reaction force during the APA period.

- Anteroposterior peak velocity of CG at the end of the first step $(V)$.

- Duration of step execution $\left(D_{\mathrm{EXE}}\right)$, i.e. time between $t_{\mathrm{HO}}$ and the time to reach $V$ $\left(t_{\mathrm{V}}\right)$.

- Duration of gait initiation $\left(D_{\mathrm{GI}}\right)$, i.e. the sum of $D_{\mathrm{APA}}$ and $D_{\mathrm{EXE}}$.

The effect of the overload on the dependent variables was evaluated by using a Student's $t$-test for paired samples. A statistical significance level at $P<0.05$ was chosen.

\section{Results}

All results are summarized in Table 1 . The APA duration $(t=-2.250, P=0.037)$, the forward impulse of the APA $(t=-4.377$, $P<0.001)$ and the duration of gait initiation $(t=-2.230, P=0.039)$

Table 1

Mean and standard deviation of the dependent variables in unloaded (UC) and overloaded $(\mathrm{OC})$ conditions.

\begin{tabular}{lccc}
\hline Parameters & UC & OC & $P$-value \\
\hline$D_{\mathrm{APA}}(\mathrm{ms})$ & $536 \pm 75$ & $573 \pm 72$ & $P=0.037$ \\
$V_{\mathrm{HO}}\left(\mathrm{m} \mathrm{s}^{-1}\right)$ & $0.22 \pm 0.06$ & $0.22 \pm 0.05$ & \\
$x P_{\max }(\mathrm{mm})$ & $-20 \pm 15$ & $-19 \pm 11$ & \\
$I m p_{\mathrm{AP}}(\mathrm{Ns})$ & $10 \pm 5$ & $13 \pm 5$ & \\
$V\left(\mathrm{~m} \mathrm{~s}^{-1}\right)$ & $1.22 \pm 0.15$ & $1.21 \pm 0.10$ & \\
$D_{\mathrm{EXE}}(\mathrm{ms})$ & $705 \pm 76$ & $709 \pm 72$ & $P=0.039$ \\
$D_{\mathrm{GI}}(\mathrm{ms})$ & $1241 \pm 101$ & $1281 \pm 81$ & \\
\hline
\end{tabular}

$D_{\mathrm{APA}}$, APA duration; $V_{\mathrm{HO}}$, anteroposterior velocity of $\mathrm{CG}$ at heel-off of the swing limb; $x P_{\max }$, maximal backward shift of $C P$ during the APA; $I m p_{\mathrm{AP}}$, forward impulse of the APA; $V$, anteroposterior peak velocity of CG at the end of the first step; $D_{\mathrm{EXE}}$, duration of step execution; $D_{\mathrm{Gl}}$, duration of gait initiation. increased significantly with the overload. There was no significant effect of the overload for the other variables.

\section{Discussion}

The addition of the overload did not modify the initial coordinates of $\mathrm{CP}$ indicating that it did not affect the weight distribution on each leg. We did observe that the overload induced an increase in the APA duration. This result was associated with a higher forward impulse of the APA $\left(\operatorname{Imp}_{\mathrm{AP}}\right)$ in OC than in UC. Previous studies have shown that a higher $I m p_{\mathrm{AP}}$ may be obtained by increasing the maximal backward shift of $C P\left(x P_{\max }\right)[13]$ and/or the APA duration [14]. In the current study, since $x P_{\max }$ did not vary, the increase of $I m p_{\mathrm{AP}}$ in $\mathrm{OC}$ may be ascribed to the lengthening of the APA. This APA adaptation allowed for the maintenance of the anteroposterior CG velocity at heel-off and hence the gait velocity at the end of the first step during gait initiation with overload.

As the duration of step execution did not vary, the lengthening of the APA caused an increase of the duration of gait initiation $\left(D_{\mathrm{GI}}\right)$ in OC. Previously, Colné et al. [6] showed that the APA and gait initiation durations did not differ between obese and normal adolescents. These disagreeing results could be because of the type of overloading (body overweight vs. external load) and of the gait velocity that was different between the obese and normal adolescents. Though it is known that the duration of gait initiation depends on anthropometric characteristics of the subjects [15], the increase of $D_{\mathrm{GI}}$ in the current study was attributed to the need to produce a greater impulse with the overload.

The present results underline that overloading challenges the propulsion that could be exacerbated in pathologic patients. Constraint-induced therapy, e.g. based on walking training with an additional load, is already conducted to improve gait in Parkinsonian patients $[7,8]$. As overloading influences the APA, it could be interesting to verify the APA adaptation of Parkinsonian subjects under overload.

In conclusion, during gait initiation with overload, able-bodied subjects modulate the APA duration to produce a higher forward impulse in order to achieve the steady-state gait at the end of the first step. These findings could have implications in clinical practice where overloading could be used to improve gait initiation 


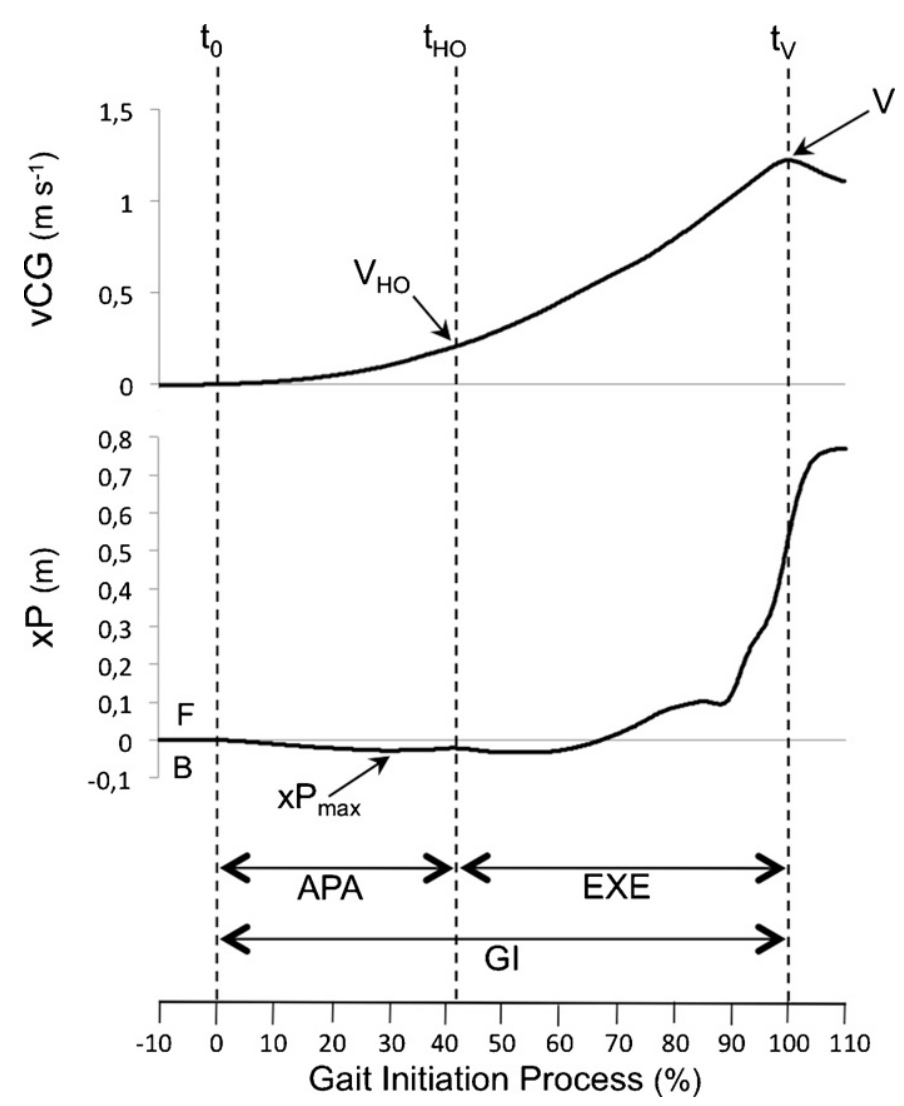

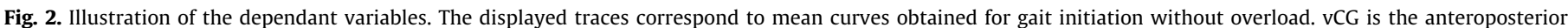

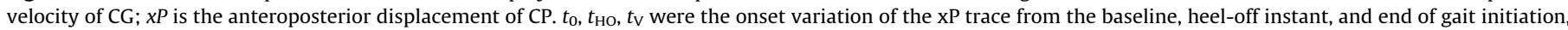

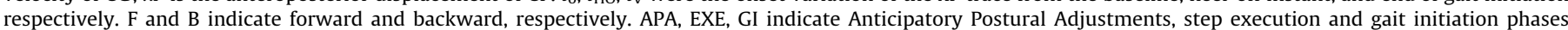

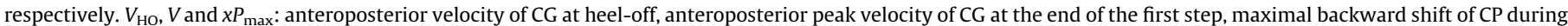
the APA, respectively.

in pathologic patients. Further investigations are needed to confirm this suggestion.

\section{Conflicts of interest statement}

None of the authors have financial or other conflicts of interest in regards to this research.

\section{Acknowledgements}

This research was supported by a grant from the University of La Reunion. We thank Dr. Eric Yiou for re-reading the manuscript and M. Isidor Padan-Lapaï for his technical assistance.

\section{References}

[1] Brenière Y, Do MC, Bouisset S. Are dynamic phenomena prior to stepping essential to walking. Journal of Motor Behavior 1987;19:62-76.

[2] Mcllroy WE, Maki BE. The control of lateral stability during rapid stepping reactions evoked by antero-posterior perturbation: does anticipatory control play a role. Gait and Posture 1999;9:190-8.

[3] Lepers R, Breniere Y. The role of anticipatory postural adjustments and gravity in gait initiation. Experimental Brain Research 1995;107:118-24.

[4] Ledin T, Fransson PA, Magnusson M. Effects of postural disturbances with fatigued triceps surae muscles or with $20 \%$ additional body weight. Gait and Posture 2004;19:184-93.
[5] Singh T, Koh M. Effects of backpack load position on spatiotemporal parameters and trunk forward lean. Gait and Posture 2009;29:49-53.

[6] Colné P, Frelut ML, Peres G, Thoumie P. Postural control in obese adolescents assessed by limits of stability and gait initiation. Gait and Posture 2008;28:164-9

[7] Filippin NT, da Costa PH, Mattioli R. Effects of treadmill-walking training with additional body load on quality of life in subjects with Parkinson's disease. Revista Brasileira de Fisioterapia 2010;14:344-50.

[8] Toole T, Maitland CG, Warren E, Hubmann MF, Panton L. The effects of loading and unloading treadmill walking on balance, gait, fall risk, and daily function in Parkinsonism. Neurorehabilitation 2005;20:307-22.

[9] Wang YT, Pascoe DD, Weimar W. Evaluation of book backpack load during walking. Ergonomics 2001;44:858-69.

[10] Corbeil P, Anaka E. Combined effects of speed and directional change on postural adjustments during gait initiation. Journal of Electromyography and Kinesiology 2011;21:734-41.

[11] Mickelborough J, van der Linden ML, Richards J, Ennos AR. Validity and reliability of a kinematic protocol for determining foot contact events. Gait and Posture 2000;11:32-7.

[12] Brenière Y, Do MC, Sanchez J. A biomechanical study of the gait initiation process. Journal De Biophysique \& Medecine Nucleaire 1981;5: 197-205.

[13] Ito T, Azuma T, Yamashita N. Anticipatory control in the initiation of a single step under biomechanical constraints in humans. Neuroscience Letters 2003:352:207-10.

[14] Tokuno CD, Sanderson DJ, Inglis JT, Chua R. Postural and movement adaptations by individuals with a unilateral below-knee amputation during gait initiation. Gait and Posture 2003;18:158-69.

[15] Brenière Y, Do MC. When and how does steady state gait movement induced from upright posture begin. Journal of Biomechanics 1986;19: 1035-40. 